\title{
Author Correction: Regulatory feedback from nascent RNA to chromatin and transcription
}

Lenka Skalska, Manuel Beltran-Nebot, Jernej Ule and Richard G. Jenner

Nature Reviews Molecular Cell Biology 18, 331-337 (2017) https://doi.org/10.1038/nrm.2017.12 Published online 08 March 2017

The original Acknowledgements section is missing funding information. The full Acknowledgements should read:

'The authors are grateful to J. Rinn for his comments on the manuscript. L.S., M.B.-N. and R.G.J. are funded by a European Research Council (ERC) Starting Grant (ChromatinRNA, 311704).'

https://doi.org/10.1038/s41580-019-0174-7 I Published online 10 September 2019

\section{Author Correction: Understanding the diversity of membrane lipid composition}

Takeshi Harayama and Howard Riezman

Nature Reviews Molecular Cell Biology 19, 281-296 (2018) https://doi.org/10.1038/nrm.2017.138 Published online 07 February 2018

The originally published article contains an error in the depiction of the structure of docosahexaenoic acid in Figure 1. The correct structure is shown below.

https://doi.org/10.1038/s41580-019-0171-x I Published online 5 September 2019

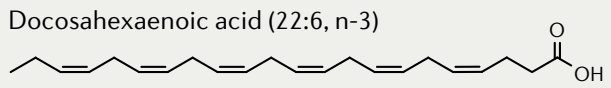

Fig. 1 | Corrected. 